\title{
I. Reply to some remarks contained in Dr. John Davy's life of Sir Humphry Davy
}

\section{Charles Daubeny M.D.}

To cite this article: Charles Daubeny M.D. (1836) I. Reply to some remarks contained in Dr. John Davy's life of Sir Humphry Davy, Philosophical Magazine Series 3, 8:46, 249-254, DOI: 10.1080/14786443608648859

To link to this article: http://dx.doi.org/10.1080/14786443608648859

册 Published online: 01 Jun 2009.

Submit your article to this journal $\asymp$

Џ Article views: 2

Q View related articles 5 
periment which $I$ have made to show that conduction has no influence in producing the appearance of polarization. For a statement of the objection I refer to my note inserted in this Journal for November last. It is thus obviated:
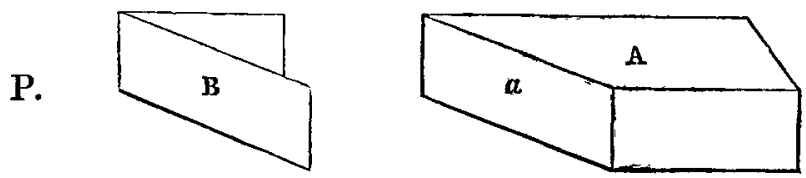

I had a tin vessel constructed of the shape shown at A, which had one surface $a$ similar in size and position to the first or polarizing plate used in my experiments, and of which the secondary radiation to the analysing plate was supposed to produce the variations observed. The analysing plate $B$ was placed between the thermo-electric pile $\mathbf{P}$ and the vessel $\mathbf{A}$, which was filled with boiling water, and which therefore produced on an enormously exaggerated scale the effects attributed to my mica plate. The vessel $A$ was then turned into the various rectangular positions as regarded $B$, without any decided difference of effect on the pile being observable; indeed, if any, that effect indicated a maximum of heat reaching the pile when the position of the surfaces was unsymmetrical, or when in polarizing, it is least. This experiment was also repeated for the case of polarization by reflexion.

By a particular process (which I will take another opportunity of describing,) I have been enabled to prepare mica plates, which, whilst they polarize more effectively than my former ones, are of extreme tenuity, so that they are almost incapable of becoming sensibly heated. With such plates I can polarize about 50 per cent. of heat wholly unaccompanied by light, and readily polarize the heat of boiling water.

I am, Gentlemen, yours truly,

Edinburgh, 12th Feb. 1836. JAMES D. Fonbes.

L. Reply to some Remarks contained in Dr. John Davy's Life of Sir Humphry Davy. By Charles Daubeny, M.D., Professor of Chemistry, \&c., Oxford.

Mr. Editor,

N Dr. Davy's lately published book, entitled "Memoirs of the Life of Sir Humphry Davy," occurs a passage reflecting on myself, on which I feel myself called upon to offer a few remarks. 


\section{Prof. Daubeny on Sir H. Davy's Theory of Volcanos,}

After noticing his brother's change of opinion with respect to the cause of volcanos, Dr. Davy proceeds as follows :

"It would hardly be supposed, that my brother's motives for modifying his views respecting the nature of volcanic action, as above stated, and for giving up in part a brilliant hypothesis, could be misinterpreted, and referred to an unworthy feeling; yet this, to my surprise, has been done, and even by Dr. Charles Daubeny, Professor of Chemistry in the University of Oxford. This Gentleman, in defending the hypothesis which he advocates, and which is precisely my brother's early hypothesis, comparing Sir H. Davy's early views with his later, says, ' The authority of Sir H. Davy may, I conceive, on this occasion, be fairly pleaded against himself, and the weight of his ipse dixit in the two latter years of his life be viewed as counterbalanced by the contrary judgement he had pronounced, apparently on the same evidence, at an earlier period; neither is it inconsistent with what we know of his character, to suppose that he should have acquired a distaste for the theory in question, when he found it seized upon and illustrated by an humble [humbler] class of inquirers." "

" This I would remark is neither generous nor just, nor even reasonable criticism. It is not generous to assign to unworthy motives, a meritorious act; for so surely may be viewed the relinquishing such an hypothesis by the author of it, when be found it not sufficiently supported by facts. It is not just, because not true, that he merely gave his ipse dixit against his early hypothesis ; in my brother's observations on volcanos, as I have mentioned, he assigned his reasons for so doing, consisting chiefly in want of the positive evidence which he expected to have met with in examining into the phænomena of active volcanos, provided the chemical theory were true. And least of all, is the criticism reasonable : it is almost absurd to suppose that my brother would relinquish his hypothesis because approved of and advocated by others. Dr. Daubeny might as well have fancied that he would have changed his views respecting chlorine, and the metallic bases of the fixed alkalies, as soon as they were seized upon and illustrated by an humbler class of inquirers."

The asperity of the above remarks seems but litlle warranted by the occasion which has called them forth.

Had Dr. Davy been aware of the sentiments I have always expressed relative to his deceased brother, he would have acquitted me of any wish to depreciate his memory, and would have felt that even in the absence of any other mode of accounting for this change of opinion, I should have abstained 
from suggesting one which would have seriously disparaged it.

But the whole amount of the charge (if charge it can be called) which I had brought against Sir H. Davy, consisted in attributing to him some degree of fickleness or caprice in the abandonment of a preconceived opinion, apparently without sufficient reason.

How far the motive suggested for this change of opinion may be consistent with the character of the individual himself, (which is now a matter of history, and not a fit subject for indiscriminate panegyric,) will best be appreciated by those who were most in his intimacy.

For my own part, as a warm admirer of his genius, though gathering my impression of his sentiments and disposition from public report; without any recollections from personal acquaintance to correet the impressions thus received, but with every disposition to extenuate the foibles of so great a philosopher; I shall sincerely rejoice, if the book now published by his brother, a small part alone of which I have as yet perused, should succeed in its proposed object of elevating the personal reputation of the individual, and thus convince the world that my interpretation of his conduct in this trivial particular has been erroneous.

Still, however, Dr. Davy must excuse me, if, from all that has yet appeared, I persist in regauding his brother's change of opinion in this instance a matter rather of taste than of judgement.

In the memoir on volcanos referred to, Sir Humphry distinctly admits that his previous theory is fully competent to explain all the phænomena*, although he concludes by assigning a preference to the other explanation as recommended by greater simplicity; a sentence which, as his biographer Dr. Paris justly observes (Life, p. 34.7), must be admitted to be rather equivocal. In his Consolations of a Philosopher he is somewhat more explicit, yet even there the only reason he assigns for preferring the theory of central heat is vague enough, being, as he thinks, "more agreeable to the analogies of things."

Having, therefore, looked in vain in either of these records of his sentiments for any attempt to show in what way "this

* "Assuming the hypothesis of the existence of such alloys of the metals of the earths as may burn into lava in the interior, the whole phænomena may be easily explained from the action of the water of the sea and air on these metals; nor is there any fact, or any of the circumstances which I have mentioned in the preceding part of this paper, which cannot be easily explained, according to that hypothesis."-Memoir on the Phænomena of Volcanos, by Sir H. Davy, Phil. Trans. 1828. [or Phil. Mag. and Annals, N.S. vol. iv. p. 85-94. EDIT.] 


\section{Prof. Daubeny on Sir H. Davy's Theory of Volcanos,}

simpler hypothesis" will account for the chemical phænomena accompanying volcanic action, and Dr. Davy himself not having supplied this desideratum, I cannot view his adoption of it in any other light at present than as a matter of taste on his part. Dr. Davy, indeed, makes his brother say, though I have not yet lighted upon the passage in which this sentiment occurs, that the chemical theory does not rest on sufficient evidence.

This however, although a ground for scepticism as to the truth of the one, would afford no reason for adopting the other; for granting that of two hypotheses both competent to explain the facts, the simpler one ought to be preferred, no competition surely can exist between them, when this can be predicated only of one.

That the chemical theory will enable us to account for the phænomena, has been shown in the memoir which called forth Dr. Davy's animadversions, and since more fully elsewhere*, and is admitted, as has been seen, in the fullest manner by Sir Humphry in the very paper to which allusion is made. Neither do I see the force of the negative evidence which Dr. Davy has produced to impugn it, for he is too conversant with volcanic operations to be ignorant that sulphuretted hydrogen is amongst its commonest products, and is too good a chemist to admit the possibility of substances like potassium or calcium in their unoxidized condition finding their way upwards in the midst of the steam, which always accompanies volcanic ejectionst. What, then, becomes of the objection, that if the hypothesis were correct, inflammable gas might probably be detected issuing from the volcano, or that some pure or uncombined alkaline or earthy inflammable basis might be discovered entangled in the lava, when the former is seen to be actually present, and the latter can so little be expected? And, whilst the presence of hydrogen, combined as it naturally would be with the sulphur which we know to exist in such situations, furnishes a striking confirmation of Sir Humphry Davy's original views, neither he, nor any other chemist, has succeeded in accounting for it according to the opposite ones.

The same may be said of the sal ammoniac, the nitrogen, and according to the simplest form of the hypothesis as ex-

* Encyclop. Metrop., art. Geology.

$\uparrow$ This objection, at least, cannot have originated with Sir Humphry, but must be the exclusive property of his brother, for in the memoir referred to we find Sir Humphry distinctly asserting, "That the extreme facility of oxidation belonging to these bodies, must prevent them from ever being found in a pure combustible state in the products of volcanic eruptions." 
pounded by Cordier, even of the water and the muriatic acid, which are noticed by Davy himself as issuing from the volcano, whose phænomena he describes.

Whatever ground, therefore, may exist for his scepticism on the subject, none certainly has been assigned for his adoption of the rival hypothesis, which, without effecting the object of explaining the facts, is saddled with assumptions equally gratuitous ; the existence of the alkaline and earthy bases in the interior of the earth, being not more unsupported by direct evidence, than that of a central fluid mass; seeing that the increasing temperature detected in descending into the bowels of the earth, may be explained quite as well by chemical processes carried on at the requisite depths, as by the hypothesis of central fluidity.

I trust I have now said enough to justify my having stated that Sir Humphry only gave his ipse dixit in support of his new hypothesis, a point which I was at that time more particularly anxious to establish, from a wish to obtain for the theory I had advocated an unprejudiced hearing, and being well aware of the weight which the deliberate judgement of such an authority as that of Sir H. Davy on a question of science would obtain with most readers. Since that time the favourable opinion expressed by the present as well as by the late President of the Geological Society with respect to the chemical theory, will have secured it a candid reception amongst naturalists; whilst the authority of one of the most distinguished of Sir Humphry Davy's living cotemporaries and rivals in science, Mons. Ampère, will vindicate its claim to respect amongst chemical philosophers.-One more word with respect to the reasonableness of imagining that Davy might choose to abandon his former hypothesis without deliberate consideration.

In the first place, considering the numberless applications of which his great discovery of the alkaline and earthy bases admitted, it is not necessary to suppose that he would regard this one with any peculiar favour. And indeed the only allusion I find to it at all in any of his earlier publications consists of four lines in a note appended to his Memoir on the Decomposition of the Earths.

Secondly, the solid character of the discoveries on which the reputation of Davy was based, would naturally make him indifferent as to the fate of a theory resting on assumptions which, whether probable or not, were such as could themselves neither be substantiated nor set aside by direct experiment.

The higher, indeed, we estimate the fame of Sir H. Davy, the less difficult will it appear to us to account for his aban- 


\section{Prof. Daubeny on Sir H. Davy's Theory of Volcanos.}

donment of his original views, and for his preference as a matter of taste for others which were calculated, from their very vagueness, to allow full scope to that imagination, which, as appears from his Consolations of a Philosopher, continued in unimpaired vigour to the last. There is, therefore, no analogy between the motives of his conduct in this case and in the question with respect to the nature of chlorine, in which Sir H. Davy might feel a just pride, as having recalled the scientific world from theory to a simple expression of facts, and thus corrected the logic of chemistry, in quite as great a degree as he extended our knowledge of this particular class of combinations.

It may be readily inferred from these remarks that I regard the chemical theory of volcanos, which it has been my humble endeavour to elucidate and to confirm, chiefly valuable by erecting a standard to which volcanic operations may be compared, and thus encouraging more minute attention to the phænomena they present. This the mere vague and general statement of their originating in central heat is not so likely to do, and hence it may perhaps be regretted, if the preference for a simpler hypothesis, or the authority of great names, should so prepossess the minds of men of science as to prevent their entertaining the views $I$ have advocated, and to induce them to dismiss the subject as altogether beyond the reach of probable conjecture *.

It is on this latter ground chiefly that I have chosen to address you, for with respect to that part of the subject which concerns myself I should have been content perhaps to leave the question at issue to the candour of the public, and to the impression which most persons will entertain, that I at least can have no desire to attribute unworthy motives to Sir $\mathrm{H}$. Davy.

Oxford, Feb. 23, 1836.

* In Dr. Thomson's Outlines of Mineralogy, Geology, and Mineral Analysis just published, I find this sentiment expressed, but the only objections stated to the chemical theory are, 1st, The specific gravity of the earth ; 2ndly, The nature of the elastic fluids emitted by volcanos. I regret, therefore, that the learned author, who has done me the honour of quoting and commending the work on volcanos I published in 1826, had not also consulted the article on Geology in the Encyclop. Metrop., to which I contributed the portion relating to volcanos, as he would have there seen the first objection fully, and I hope fairly, treated, and the latter shown to be quite in accordance with the theory.

The low specific gravity of the metals of the alkalies appears to operate against the reception of the theory in the minds of many; yet if it can be shown that the bases of those volcanic products which appear upon the surface have collectively a greater specific gravity than the mass resulting from their union with oxygen, I cannot see wherein the force of this objection resides. 